\title{
Effect of Nanoparticle Content on the Microstructural and Mechanical Properties of Forged and Heat-Treated TiC/2219 Nanocomposites
}

\author{
Yilong Yang ${ }^{1,2}$, Ripeng Jiang ${ }^{1,2, *}$, Xiaoqian $\mathrm{Li}^{1,2}$, Yun Zhang ${ }^{1,2}$ and Ruiqing $\mathrm{Li}^{1,2}$ \\ 1 Light Alloy Research Institute, Central South University, Changsha 410012, China \\ 2 National Key Laboratory of High Performance Complex Manufacturing, Central South University, \\ Changsha 410012, China \\ * Correspondence: jiangripengcsu@163.com; Tel.: +86-151-7314-9455
}

Received: 9 August 2019; Accepted: 2 September 2019; Published: 4 September 2019

check for updates

\begin{abstract}
In this study, castings of TiC nanoparticle reinforced 2219 aluminum matrix composites with different TiC nanoparticle contents $(0,0.5,0.9,1.3$, and $1.7 \mathrm{wt} . \%)$ prepared using an ultrasound-assisted stirring technology were deformed by multidirectional forging at $510{ }^{\circ} \mathrm{C}$ followed by $\mathrm{T} 6$ aging treatment. The microstructural evolution and mechanical properties of the 2219 alloy and its composites were investigated and compared. Optical microscopy and scanning electron microscopy revealed that the composite with $0.9 \mathrm{wt} . \% \mathrm{TiC}$ nanoparticle content possessed finer grains and the lowest amount of $\mathrm{Al}_{2} \mathrm{Cu}$ phases. The electron backscattered diffraction (EBSD) was used to characterize the sub-grains. The precipitation microstructures of the 2219 alloy and composites with different nanoparticle contents were characterized by differential scanning calorimetry and transmission electron microscopy. It was found that $0.9 \mathrm{wt} . \% \mathrm{TiC} / 2219$ nanocomposites contained the highest amount of $\theta^{\prime \prime}$ and $\theta^{\prime}$ phases with shorter lengths. This might imply that the nanoparticles uniformly dispersed in the matrix could facilitate the precipitation of $\theta^{\prime \prime}$ and $\theta^{\prime}$ phases during aging. Thus, the $0.9 \mathrm{wt} . \% \mathrm{TiC} / 2219$ nanocomposite showed the best mechanical properties. The ultimate tensile strength, yield strength, and elongation of the $0.9 \mathrm{wt} . \% \mathrm{TiC} / 2219$ nanocomposite increased by $24.2,46.1$, and $37.2 \%$, respectively, compared to those of the 2219 alloy.
\end{abstract}

Keywords: aluminum matrix nanocomposite; forging; heat treatment; precipitation phase; mechanical properties

\section{Introduction}

Aluminum matrix composites are a type of advanced materials, which have advantages that traditional materials do not have, such as their light weight, high specific strength, high specific modulus, low coefficient of thermal expansion, and good wear resistance [1-4]. 2219Al-Cu alloys are particularly attractive materials for aerospace and automotive applications owing to their low density and high strength, where the strength to weight ratio is a major design consideration. Titanium carbide (TiC) nanoparticles have excellent chemical and physical properties such as high chemical, thermal stability, abrasion resistance, creep resistance, low density, and low coefficient of thermal expansion. They are often used as the discontinuous particle reinforcement phase $[5,6]$. However, composite castings do not meet the requirements of industrial applications, requiring the workpieces to be deformed. After the deformation process, the performance of workpieces is greatly improved. There are many kinds of deformation processes for as-cast workpieces, such as forging, cold rolling, and extrusion. Some researchers have studied the effects of cold rolling and extrusion on the structure and mechanical properties of the composites [7-12]. Compared with cold rolling and extrusion 
processes, forging is an ancient and important method of metal forming. It offers many advantages such as superior mechanical properties, and near net shape production with negligible material wastage. Moreover, the application of forging is not limited by the initial shape of the castings. Forged workpieces not only have high strength and good grain orientation but can meet the industrial requirements without additional processing, thus greatly saving materials [13].

Some researchers have studied the influence of forging on the properties and microstructure of composites reinforced by different kinds of particles. However, most of these composites were reinforced by micro-particles. Ismail et al. [14] showed that the yield strength and tensile strength of SiCp $(15-30 \mu \mathrm{m})$ reinforced aluminum composites improved by $100 \%$ and $40 \%$, respectively, after forging. Moreover, the yield strength and tensile strength of the composites increased with the increasing volume fraction of SiCp up to 17 vol.\% and then decreased with further addition of reinforcement. Bharathesh et al. [15] reported that the microhardness and tensile strength of a hot-forged $\mathrm{Al}-8 \mathrm{wt} . \% \mathrm{TiO}_{2}(20-60 \mu \mathrm{m})$ composite were higher than those of the matrix material, whereas the ductility was lower. Ceschini et al. [16] investigated the effect of hot forging on the microstructure and tensile properties of AA2618 aluminum alloys reinforced with 20 vol. $\% \mathrm{Al}_{2} \mathrm{O}_{3}$ $(20 \mu \mathrm{m})$ at room temperature. The hardness, tensile strength, elastic modulus, and tensile elongation of the forged samples increased. Narayana Murty et al. [17] optimized the hot working process condition for $6061 \mathrm{Al}-\mathrm{SiC}$ and $6061 \mathrm{Al}-\mathrm{Al}_{2} \mathrm{O}_{3}$ and identified the stable and unstable regions in the processing maps from the present instability condition. Other researchers have studied the forgings of different particle reinforced composites prepared by different methods. The forging process can break some of the agglomerated particles, thus facilitating uniform distribution of particles in the matrix and improving the properties of the material [18-20]. However, nanocomposites, especially the forged and heat-treated composites reinforced by TiC nanoparticle $(40-80 \mathrm{~nm})$, were rarely studied. Few papers have studied the effect of $\mathrm{TiC}$ nanoparticle on precipitation of $\theta^{\prime \prime}$ and $\theta^{\prime}$ phases to explain the improvement of properties of TiC/2219 alloy nanocomposites.

This study investigated the effects of TiC nanoparticle content on the microstructure and mechanical properties of $\mathrm{TiC} / 2219$ nanocomposites. We focused on the impact of $\mathrm{TiC}$ nanoparticle content on the precipitation of $\theta^{\prime \prime}$ and $\theta^{\prime}$ phases and further explained why the properties of composites were improved. The as-cast 2219 alloy and composites with different nanoparticle contents were prepared by ultrasonic-assisted stirring and then forged by the same forging process followed by the same T6 heat treatment. Finally, the microstructures and mechanical properties of the 2219 alloy and its composites were studied. The effect of different nanoparticle contents on the microstructural and mechanical properties was analyzed and discussed from the viewpoint of $\theta^{\prime \prime}$ and $\theta^{\prime}$ phase precipitation.

\section{Materials and Methods}

In this study, the 2219Al alloy with a nominal chemical composition of $\mathrm{Al}-5.8 \% \mathrm{Cu}-0.2 \% \mathrm{Mn}-0.1 \%$ $\mathrm{Zr}-0.05 \% \mathrm{~V}-0.35 \% \mathrm{Fe}-0.2 \% \mathrm{Si}-0.02 \% \mathrm{Mg}-0.1 \% \mathrm{Zn}$ (wt.\%) was selected as the matrix alloy, and the TiC nanoparticles (purity: 99.99\%, hexahedron shape, diameter 20-100 nm, ShangHai NaiOu Company, Shanghai, China) were used as the reinforcements as shown in Figure 1. The TiC/2219 nanocomposite was prepared by an ultrasound-assisted stirring technology that could promote the wetting of particles and melt, which could facilitate the incorporation of the nanoparticles into the melt. Ultrasonic melt treatment was exerted through a sonotrode that was driven by a high power ultrasonic generator (input frequency, $20 \mathrm{kHz}$; input power $2.5 \mathrm{~kW}$ ). The output power and current were $400 \mathrm{~W}$ and $6 \mathrm{~A}$, respectively. Sonotrode, made of Ti alloy [21,22], was immersed at a position of $30 \mathrm{~mm}$ below the melt surface and vibrated for $15 \mathrm{~min}$ in $700{ }^{\circ} \mathrm{C}$. The microstructures and properties of composite castings had been studied in the author's previous work [23]. 

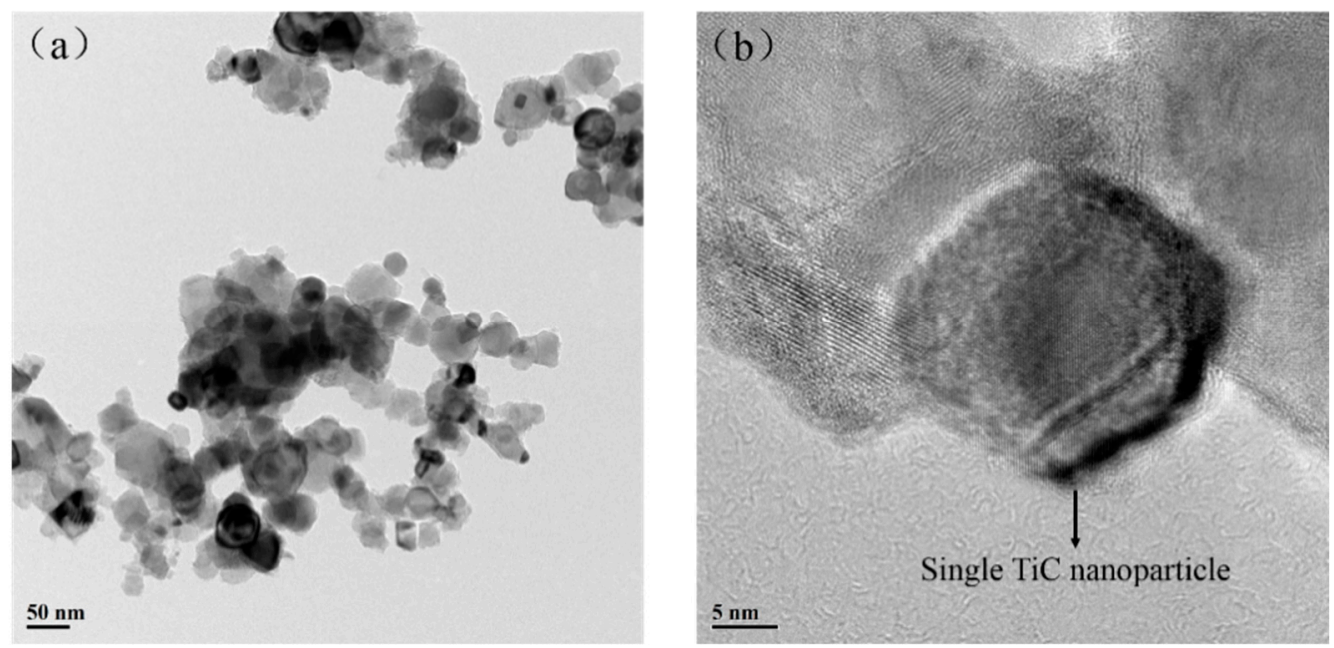

Figure 1. The TEM examination of as-received TiC nanoparticles: (a) morphology of TiC nanoparticles, and (b) high-resolution TEM image of one TiC nanoparticle.

$\mathrm{TiC} / 2219$ nanocomposite samples with different nanoparticle contents $(0,0.5,0.9,1.3$, and $1.7 \mathrm{wt} . \%)$ were severely deformed by multidirectional forging at $510{ }^{\circ} \mathrm{C}$ with a compression speed of $10 \mathrm{~mm} / \mathrm{s}$ using a $40 \mathrm{MN}$ numerically-controlled hydraulic press [24]. The mold temperature for forging was $460{ }^{\circ} \mathrm{C}$. These five as-cast billets were cut into $80 \times 80 \times 90 \mathrm{~mm}^{3}$ cuboids. A coating was applied on their surfaces with a brush to prevent the sample from sticking to the mold. Then, the samples were heated to $540{ }^{\circ} \mathrm{C}$ in a furnace for $2 \mathrm{~h}$. In each upset forging, the specimens were compressed along different axes with 50\% height reduction, and then cooling at room temperature. Figure 2 shows a schematic diagram of the forging process. Five forging processes were applied, wherein the force used for the first to the fourth forging processes was F1, and that for the last forging process was F2 to reduce the deformation rate achieving a relatively large size. The forged samples were subjected to T6 heat treatment, involving solution treatment at $530^{\circ} \mathrm{C}$ for $2 \mathrm{~h}$, water quenching, and ageing at $163^{\circ} \mathrm{C}$ for $30 \mathrm{~h}$, and cooling at room temperature. The forged and heat-treated samples were used to analyze the microstructure and mechanical properties.

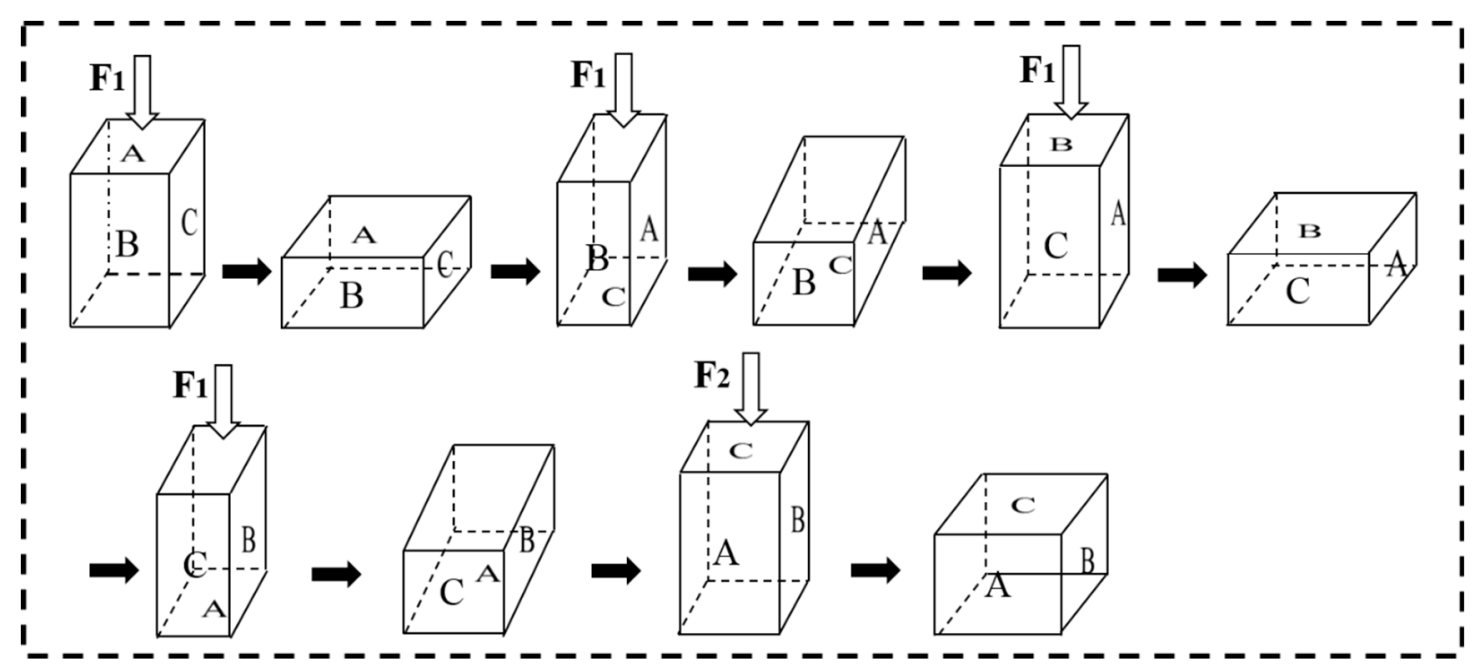

Figure 2. Schematic of the multidirectional forging process.

The forged and heat-treated 2219 alloy and composite samples were further used to study the effect of the nanoparticles on the precipitation phase. Specimens were extracted from the middle region in the same axial direction of these 5 samples. Optical microscopy (OM; DSX50240, OLYMPUS, Beijing, China) was performed to observe the grain size. These samples were mechanically ground, 
polished, and etched using the Keller solution for OM. Scanning electron microscopy (SEM; JSM-7600F, JEOL, Shanghai, China) was performed to observe the $\mathrm{Al}_{2} \mathrm{Cu}$ phases in the multidirectional-forged heat-treated matrix. Specimens for SEM were prepared by mechanical grinding and polishing. Electron Backscatter Diffraction (EBSD) was used to investigate the sub-grain. The samples of EBSD were ground and then electro-polished in a solution of 30\% nitric acid and 70\% methanol at $18 \mathrm{~V}$ for $50 \mathrm{~s}$. HKL Channel 5 software was used to analyze the EBSD data. Transmission electron microscopy (TEM; JEM2100, JEOL, Hillsboro, OR, USA) was conducted to determine the effect of nanoparticles on the precipitation phases. TEM specimens were prepared by slicing the samples to $0.5 \mathrm{~mm}$ thickness and then grinding to $50 \mu \mathrm{m}$ thickness. After grinding, the slices were punched into $3 \mathrm{~mm}$ diameter disks and then thinned by an ion beam to about $5 \mu \mathrm{m}$. Differential scanning calorimetry (DSC; Perkin-Elmer 8000 , Beijing, China) was performed to determine the role of the nanoparticles on the precipitation kinetics of the strengthening phases. The DSC samples were polished with $400 \mathrm{~W}$ metallographic sandpaper to a thickness of $1 \mathrm{~mm}$. Then, $15 \mathrm{mg}$ of slices were removed with scissors and loaded on the DSC system. Experiments were performed at a constant heating rate of $10^{\circ} \mathrm{C} / \mathrm{min}$ under a protective atmosphere of pure nitrogen. Room-temperature tensile strength, yield strength, and elongation of forged and heat-treated 2219 alloy, and nanocomposite specimens were determined using a tensile tester (AG-IC100KN, Shimadzu, Changchun, China) at a displacement speed of $2 \mathrm{~mm} / \mathrm{min}$. The prepared samples were non-proportional according to national standards [25]. Three specimens of each sample were tested and the average values were calculated as the tensile properties. In addition, the fracture behaviors of the samples were studied.

\section{Results and Discussion}

\subsection{Microstructure}

Figure 3 shows the microstructures of the forged and heat-treated TiC/2219 nanocomposites with different TiC nanoparticle contents (0, 0.5, 0.9, 1.3, and $1.7 \mathrm{wt.} \%)$. Compared with the 2219 alloy, the grains in all the nanocomposites became refined with the addition of TiC nanoparticles (Figure 3 ). As shown in Figure 3a, the grain size of the 2219 alloy was larger than that of the composites. As shown in Figure $3 b-f$, with an increase in particle content, the grain size of the composites decreased and then increased. The grain size of the 2219 alloy was $195 \mu \mathrm{m}$. At particle contents of $0.5 \mathrm{wt} . \%$ and $0.9 \mathrm{wt} . \%$, the grain sizes were $163 \mu \mathrm{m}$ and $78 \mu \mathrm{m}$, respectively. In addition, it was observed that a small amount of nanoparticles aggregated at the grain boundary of the $0.9 \mathrm{wt} . \% \mathrm{TiC} / 2219$ nanocomposites as shown in Figure $3 \mathrm{c}$ in the enlarged part (1). Figure $4 \mathrm{a}$,b shows that the $\mathrm{TiC}$ nanoparticles aggregated at the grain boundaries of the $0.9 \mathrm{wt} . \% \mathrm{TiC} / 2219$ nanocomposite. The EDS analysis of the agglomeration is shown in Figure 4d. The TiC nanoparticles dispersed in the matrix (Figure 4c). However, with further increase in particle content to $1.3 \mathrm{wt} . \%$ and $1.7 \mathrm{wt} . \%$, the grain size increased to $96 \mu \mathrm{m}$ and $114 \mu \mathrm{m}$, respectively. Moreover, at a particle content of $1.7 \mathrm{wt} . \%$, a large amount of sub-grains and agglomeration of nanoparticles appeared in the crystal and at the grain boundaries, respectively, as shown in Figure 3e and enlarged part (3). The EBSD orientation maps also showed sub-grains of TiC/2219 composites with different $\mathrm{TiC}$ nanoparticle contents, including $0 \mathrm{wt} . \%, 1.3 \mathrm{wt} . \%$, and $1.7 \mathrm{wt} . \%$ as shown in Figure 5 . The white lines in the images were small angle grain boundaries. The existence of sub-grains was thus proved.

Previous studies of as-cast samples found that the nanoparticles could uniformly disperse in the $0.9 \mathrm{wt} . \% \mathrm{TiC} / 2219$ nanocomposite. As the particle content continued to increase, the particles enriched at the grain boundaries after reaching the threshold of particle incorporation into the matrix (Figure 3e). Figure $3 \mathrm{c}$ also shows the nanoparticles agglomerate at grain boundaries. This might be because each direction was only pierced once during the forging process, resulting in a low deformation rate, which could not induce an effective force to break the agglomerated particles. The same conclusion can be found in the literature [16]. The changes in the grain sizes of different samples were because an appropriate amount of nanoparticles could serve as heterogeneous nucleating centers during the 
solidification process, thus decreasing the grain size. The more nanoparticles in the matrix, the more heat they absorbed, which led to a lower energy of deformation being stored in the material; thus, a strong dynamic recovery could be achieved [26]. Therefore, the number of nucleation sites formed during the solution treatment was small and most of the stored deformation energy could be used for grain growth; thus, the grain size gradually increased. With the continuous addition of particles, the storage energy, and the driving force of recrystallization further reduced, resulting in incomplete crystallization and sub-grains. In addition, dislocation loops were found around the precipitations as shown in Section 3.3. The extra dislocation caused by the nanoparticle could provide the driving force for recrystallization. Dislocation loops are shown in the following chapter. The evolution of the grain structure is not the subject of this study but will be discussed in another report.
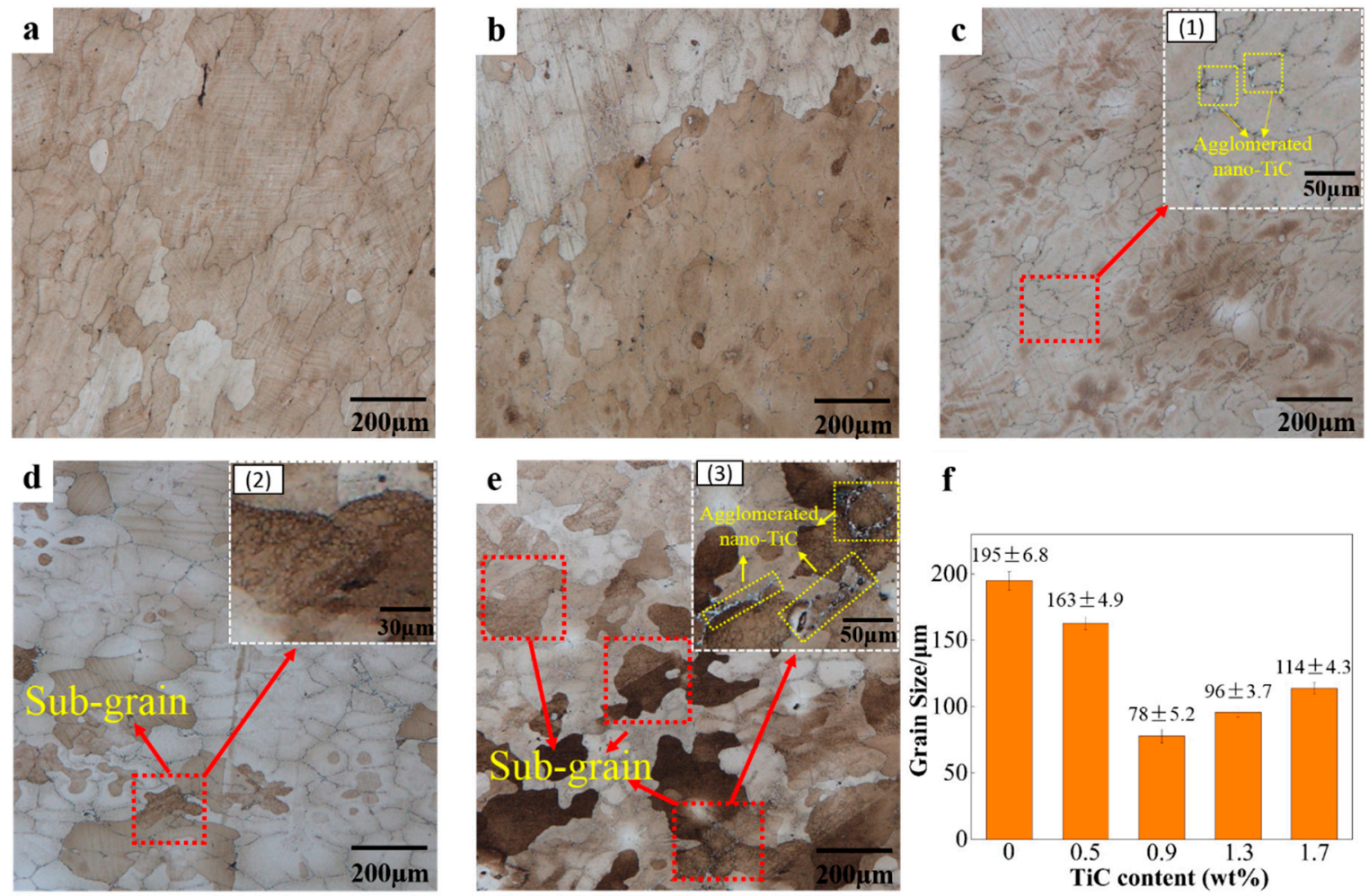

Figure 3. Optical microscopy (OM) images of forged and heat-treated TiC/2219 nanocomposites with different nanoparticle contents: (a) 0 wt.\%, (b) 0.5 wt.\%, (c) 0.9 wt.\%, (d) 1.3 wt.\%, and (e) 1.7 wt.\%. Inset (1) and (2) present the agglomerated TiC nanoparticles along the grain boundaries and sub-grains, respectively, and (3) represents the serious nanoparticle agglomeration along the grain boundaries; (f) is the average grain size of the $\mathrm{TiC} / 2219$ nanocomposites.

Figure 6 shows the SEM micrographs of the forged and heat-treated 2219 alloy and TiC/2219 nanocomposites with different TiC nanoparticle contents. The SEM images of the 2219 alloy shown in Figure 6a reveal a large number of coarse and continuous $\mathrm{Al}_{2} \mathrm{Cu}$ phases along the grain boundaries, showing a network structure. Figure $6 \mathrm{~b}, \mathrm{c}$ show that with the increased TiC nanoparticle content, the coarse $\mathrm{Al}_{2} \mathrm{Cu}$ phases in the matrix begin to decrease, forming discontinuous fine $\mathrm{Al}_{2} \mathrm{Cu}$ phases. When the particle content increased to $1.3 \mathrm{wt} \% \%$ and $1.7 \mathrm{wt} \%$ (Figure $6 \mathrm{~d}, \mathrm{e}$ ), the amount of $\mathrm{Al}_{2} \mathrm{Cu}$ phases increased and many coarse network structures gradually formed. Figure $6 f$ shows the area fraction of $\mathrm{Al}_{2} \mathrm{Cu}$ phases in these samples. The area distributions of the $\mathrm{Al}_{2} \mathrm{Cu}$ were measured by the software named Image pro plus. The SEM images of $\mathrm{Al}_{2} \mathrm{Cu}$ were put into the software, then the software recognized different colors of the SEM image calculating the percentage of different color areas automatically. The amount of $\mathrm{Al}_{2} \mathrm{Cu}$ phase in the $0.9 \mathrm{wt} . \% \mathrm{TiC} / 2219$ nanocomposites was the smallest. With increasing $\mathrm{TiC}$ nanoparticle content from $0 \mathrm{wt} . \%$ to $0.9 \mathrm{wt} \%$, the area fraction of the $\mathrm{Al}_{2} \mathrm{Cu}$ 
phases decreased from $2.19 \%$ to $0.26 \%$ due to dissolution into the matrix. However, with increasing TiC nanoparticles content from $1.3 \mathrm{wt} . \%$ to $1.7 \mathrm{wt} . \%$, the area fraction of the $\mathrm{Al}_{2} \mathrm{Cu}$ phases increased from $0.83 \%$ to $1.16 \%$. As shown in Figure 3, the grain size changed with the addition of nanoparticles. The smaller the grain size, the smaller the grain boundary. As a result, at a certain solution temperature, the $\mathrm{Al}_{2} \mathrm{Cu}$ phases at the grain boundary of small grains could easily melt into the matrix than at the grain boundary of large grains. Hence, the phenomena shown in Figure $6 b, c$ could occur. As the particle content increased, more nanoparticles concentrated at the grain boundaries, thereby inhibiting the dissolution of $\mathrm{Al}_{2} \mathrm{Cu}$ phases, as shown in Figure $6 \mathrm{~d}$,e. The difference of the area fraction of $\mathrm{Al}_{2} \mathrm{Cu}$ phases in different samples also directly indicated the influence of different $\mathrm{TiC}$ nanoparticle contents on the precipitation phase. The more precipitated phases there were, the more $\mathrm{Al}_{2} \mathrm{Cu}$ phases precipitated into the crystals and the smaller the area fraction of $\mathrm{Al}_{2} \mathrm{Cu}$ phases was. This is further explained in Section 3.2 .
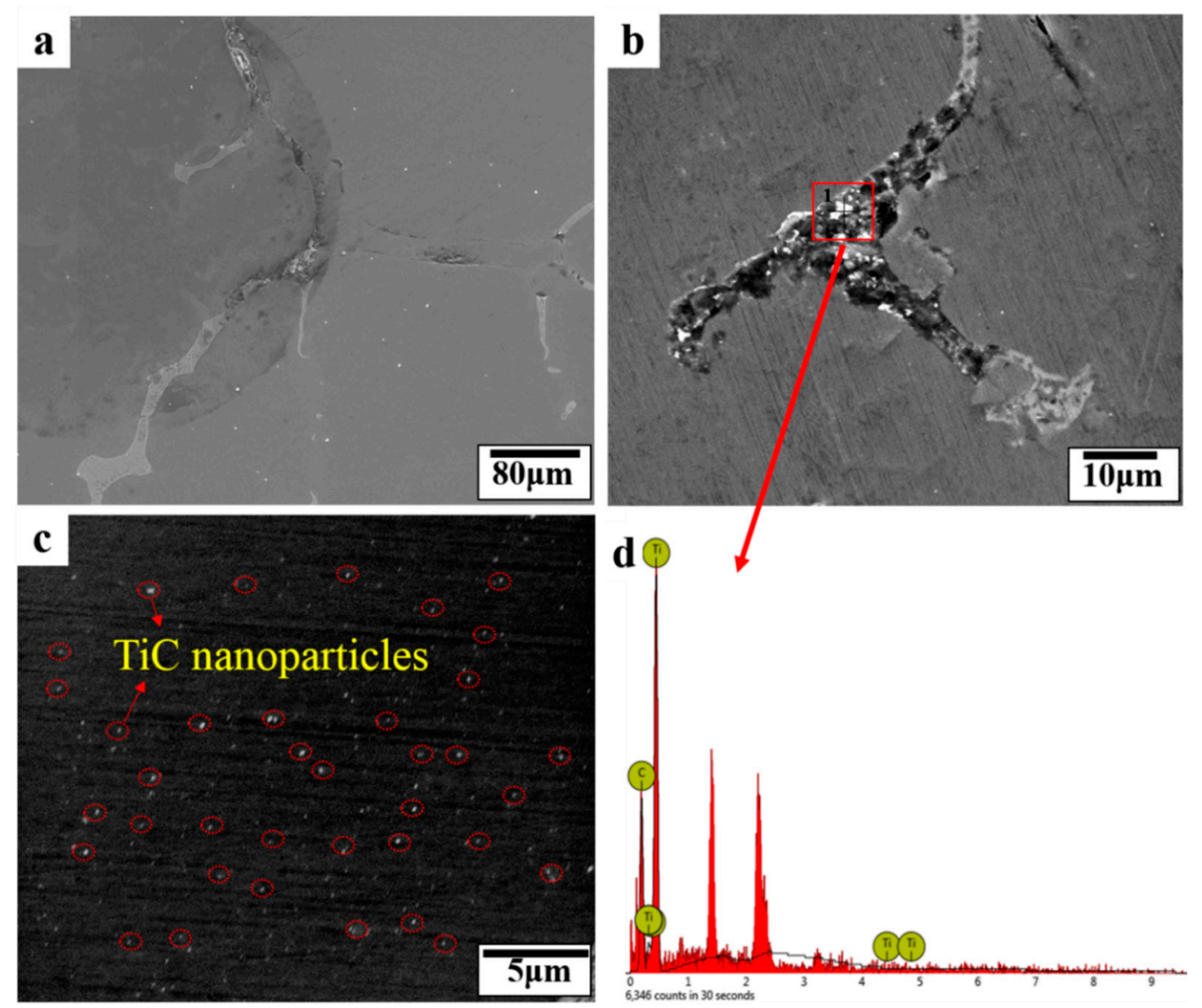

Figure 4. SEM micrographs of (a) aggregated TiC nanoparticles along the grain boundaries of 0.9 wt.\% Table 2219. nanocomposite; (b) magnification SEM micrograph of the microstructure; (c) TiC nanoparticles dispersed in the matrix; (d) Energy Dispersive Spectrometer (EDS) results corresponding to the phase. 

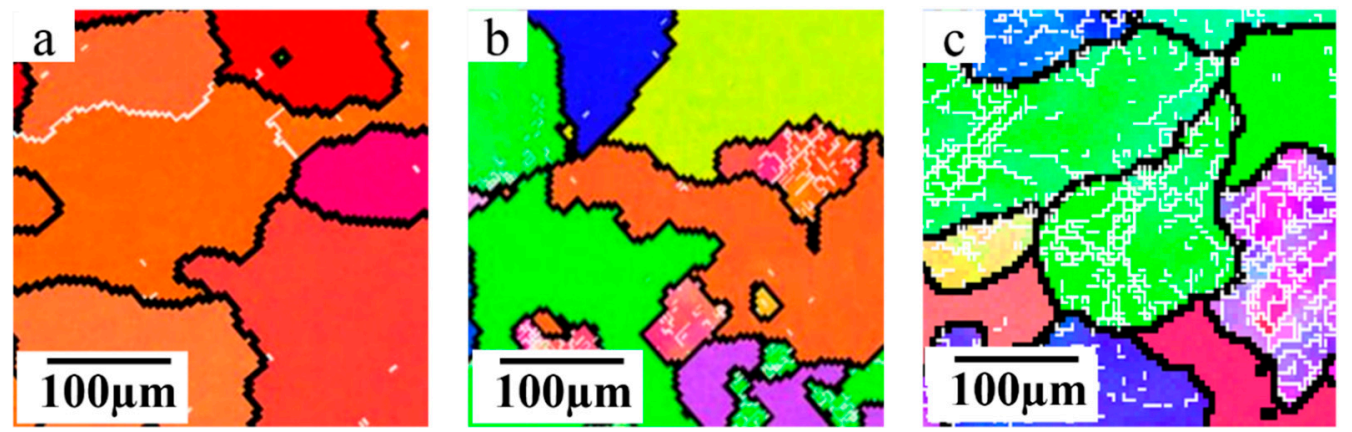

Figure 5. Electron backscatter diffraction (EBSD) orientation maps showing the sub-grain of TiC/2219 nanocomposites with different $\mathrm{TiC}$ nanoparticles contents: (a) $0 \% \mathrm{TiC}$, (b) $1.3 \% \mathrm{TiC}$, and (c) $1.7 \% \mathrm{TiC}$.
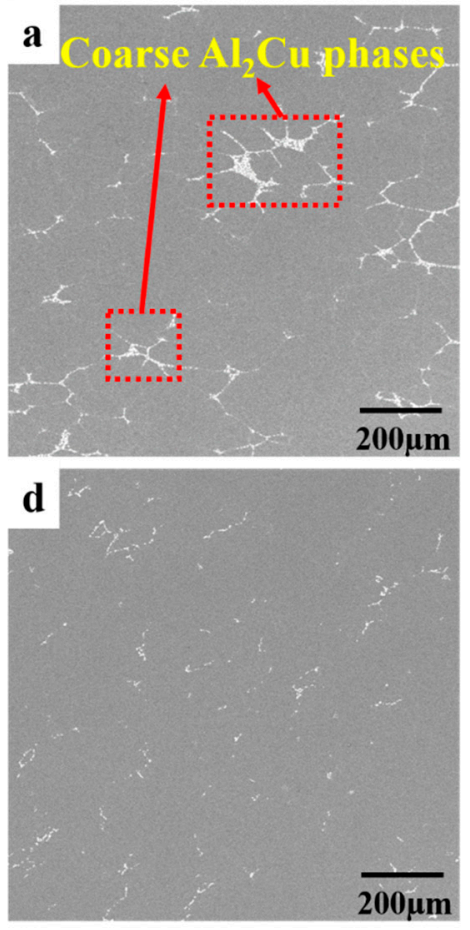
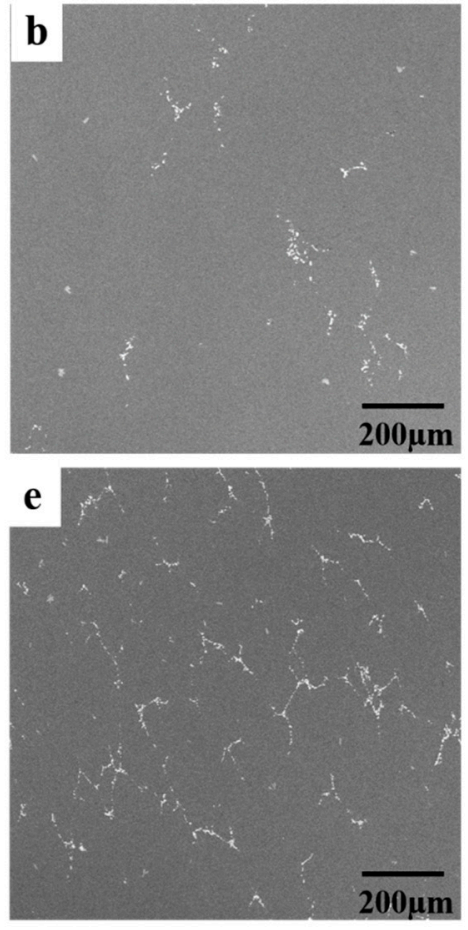
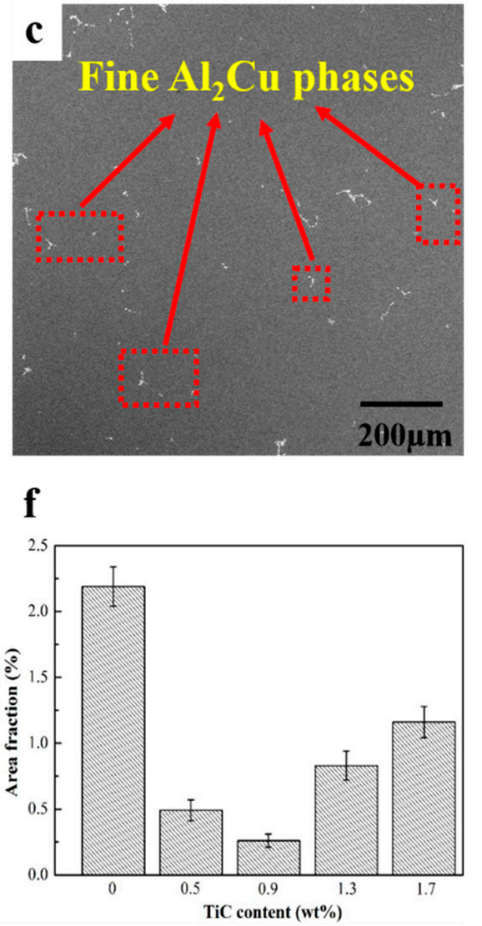

Figure 6. SEM images of the forged and heat-treated TiC/2219 nanocomposite with different nanoparticle contents: (a) 0 wt.\%, (b) 0.5 wt.\%, (c) 0.9 wt.\%, (d) 1.3 wt.\%, and (e) 1.7 wt.\%; (f) the area fraction of $\mathrm{Al}_{2} \mathrm{Cu}$ phases in $\mathrm{TiC} / 2219$ nanocomposites.

\subsection{DSC Analysis}

Figure 7 shows the DSC curves of the forged and heat-treated TiC/2219 nanocomposites with different TiC nanoparticle contents. DSC was performed to determine the types of precipitated phases and show their relative contents in the matrix. In the DSC curve of the aluminum alloy, the endothermic peak represents the dissolution of phases and the exothermic peak represents the precipitation and growth of the precipitated phases. The DSC curves of the 2219 alloy and composite materials with different contents of $0.5,0.9,1.3$, and $1.7 \mathrm{wt} . \%$ show endothermic peaks at 549.94, 550.8, 550.32, 550.74, and $550.82{ }^{\circ} \mathrm{C}$, respectively (Figure $7 \mathrm{a}$ ). The endothermic peaks of the composites shifted toward higher temperatures compared with that of the 2219 alloy due to an increase in thermal stability after addition of TiC nanoparticles. This is also probably caused by the variable alloying compositions, the externally added $\mathrm{TiC}$ particles, the potential as-cast impurity, and the specific experimental process. The addition of TiC slightly increases the solution temperature of the alloy. The precipitated phase at this point was the $\theta$ phase that was the $\mathrm{Al}_{2} \mathrm{Cu}$ phase. The areas of endothermic and exothermic peaks could reflect the enthalpy of phase transformation in alloys. The larger the volume fraction of the second 
phase in the alloys, the larger the area of corresponding peaks. The area of endothermic $\mathrm{W}$ represented the amount of $\mathrm{Al}_{2} \mathrm{Cu}$ phase. This proved that the $\mathrm{Al}_{2} \mathrm{Cu}$ phase in the composite was lower than in the 2219 alloy. The endothermic peak $\mathrm{W}$ for sample $\mathrm{A}$ was noticeably bigger than other composites (Figure 7a), while the endothermic peak $\mathrm{W}$ of curve $\mathrm{C}$ was the smallest and the endothermic peak $\mathrm{W}$ of curve $\mathrm{A}$ was the biggest. This proved that a greater amount of $\mathrm{Al}_{2} \mathrm{Cu}$ phase was present in sample A than in sample B, C, D, and E. This was consistent with the conclusion drawn from the results shown in Figure 6. And Figure $7 \mathrm{~b}$ shows an endothermic peak $\mathrm{V}$ and an exothermic peak $\mathrm{M}$ in each curve. The endothermic peak V represented the dissolution of the $\theta^{\prime \prime}$ phase [27] and was largest for sample $C$. The exothermic peak $\mathrm{M}$ of sample $\mathrm{C}$ was the largest as well. These results indicated that $\mathrm{TiC}$ nanoparticle content of $0.9 \mathrm{wt} . \%$ effectively promoted the precipitation of $\theta^{\prime \prime}$ and $\theta^{\prime}$ phases. The amounts of $\theta^{\prime \prime}$ and $\theta^{\prime}$ phases played important roles in the mechanical strength of the $0.9 \mathrm{wt} . \%$ $\mathrm{TiC} / 2219$ composite. The micro-morphology of $\theta^{\prime \prime}$ and $\theta^{\prime}$ phases is shown in Figure 8.
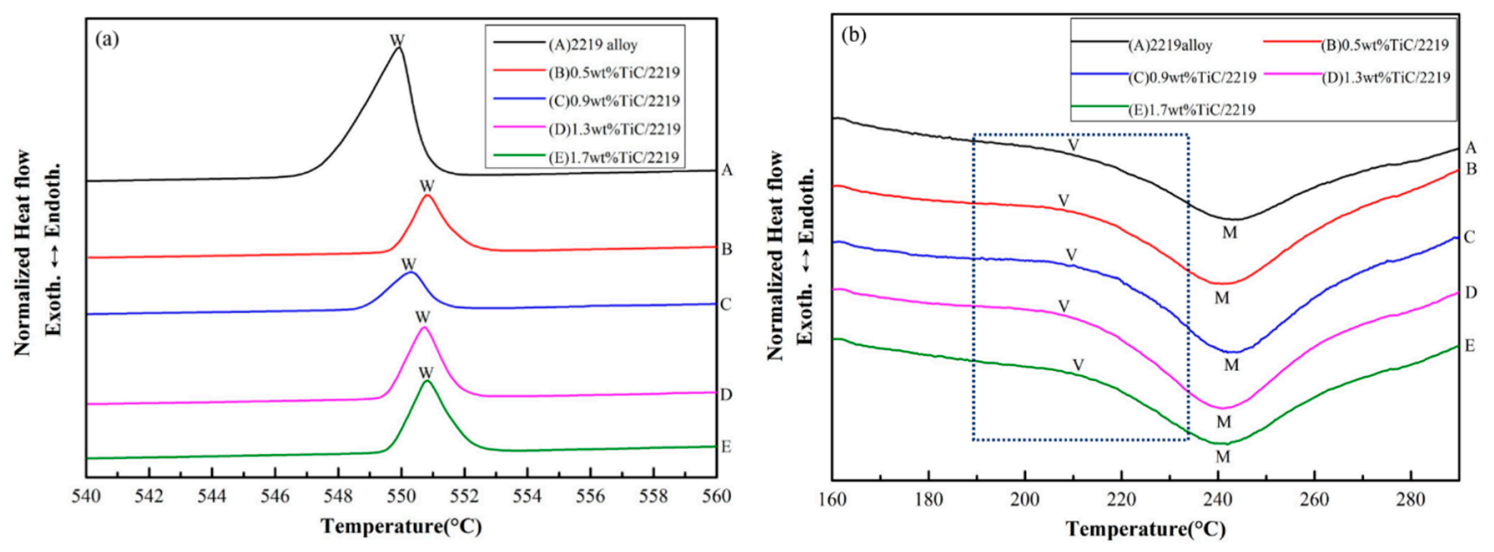

Figure 7. DSC heating curves of the forged and heat-treated TiC/2219 nanocomposite samples: (a) endothermic peak $\mathrm{W}$ represents the dissolution of phases, and (b) exothermic peak $\mathrm{M}$ represents the precipitation and growth of the precipitated phases.

\subsection{TEM Observations}

In an $\mathrm{Al}-\mathrm{Cu}$ alloy, the typical aging precipitation sequence is as follows: Supersaturated solid solution $\rightarrow$ GP zone $\rightarrow \theta^{\prime \prime} \rightarrow \theta^{\prime} \rightarrow \theta\left(\mathrm{Al}_{2} \mathrm{Cu}\right)$ [28]. The $\theta^{\prime}$ phases are formed on the $\{100\}_{\alpha-\mathrm{Al}}$ planes in $\mathrm{Al}-\mathrm{Cu}$ alloys [29]. Figure 8 shows the TEM bright-field micrographs of the plate-shaped $\theta^{\prime}$ phases in the forged 2219 alloy and composites with different nanoparticle contents subjected to the same T6 heat treatment. Figure 8 a shows the presence of very few $\theta^{\prime}$ precipitates in the matrix. The average diameter and thickness of the $\theta^{\prime}$ phases in the 2219 alloy were about $124 \mathrm{~nm}$ and $6 \mathrm{~nm}$, respectively, but the amount of $\theta^{\prime}$ phases was very small (Figure $8 \mathrm{~g}$ ). At a particle content of $0.9 \mathrm{wt} . \%$, a large number of dense $\theta^{\prime \prime}$ and $\theta^{\prime}$ phases were present in the matrix (Figure $8 \mathrm{c}$ ), and the distribution of $\theta^{\prime}$ phase was more homogeneous. The average diameter and thickness of the $\theta^{\prime}$ phases in it were about $171 \mathrm{~nm}$ and $7 \mathrm{~nm}$, respectively (Figure 8i). With an increase in the TiC nanoparticle content, the number of $\theta^{\prime}$ phases began to decrease (Figure $8 \mathrm{~d}, \mathrm{e}$ ). The average diameter and thickness of the $\theta^{\prime}$ phases in $1.3 \mathrm{wt} . \%$ $\mathrm{TiC} / 2219$ and $1.7 \mathrm{wt} . \% \mathrm{TiC} / 2219$ composites were about $213 \mathrm{~nm}, 8 \mathrm{~nm}$, and $287 \mathrm{~nm}, 8 \mathrm{~nm}$, respectively (Figure 8j,k). Because the grain size of the composite was smaller than that of the alloy, the solution distance of the $\mathrm{Cu}$ atom became shorter during aging [30]. As described in Section 3.1, the area fraction of $\mathrm{Al}_{2} \mathrm{Cu}$ was the largest. Therefore, compared with other composites, a large number of agglomerated $\mathrm{Al}_{2} \mathrm{Cu}$ particles were not conducive to the precipitation in the precipitated phase under the same heat treatment process. In addition, dislocation loops were found around the precipitations (Figure 8e). Figure $8 \mathrm{f}$ shows the TEM morphology of TiC nanoparticles in the matrix. It can be seen that a particle content of $0.9 \mathrm{wt} . \%$ is beneficial for the precipitation of $\theta^{\prime \prime}$ and $\theta^{\prime}$ phases. This was also confirmed from Figure $7 \mathrm{~b}$. The addition of $0.9 \mathrm{wt} . \% \mathrm{TiC}$ nanoparticles promoted the precipitation of the $\theta^{\prime}$ phase due to the presence of a larger amount of nanoparticles in the matrix. Hardy [31] 
considered that atoms considerably larger than Al could affect the nucleation of precipitated phases. The diameter of $\mathrm{TiC}$ nanoparticle $(20-100 \mathrm{~nm})$ was larger than that of the $\mathrm{Al}$ atom $(0.143 \mathrm{~nm})$. When $\mathrm{TiC}$ nanoparticles entered the Al matrix, it inevitably caused crystal lattice distortion and increased the system's energy. To maintain low system energy, more oversaturated vacancies might aggregate around the $\mathrm{TiC}$ nanoparticles. With the addition of $1.3 \mathrm{wt} \%$ and $1.7 \mathrm{wt} . \% \mathrm{TiC}$, the number of precipitated phases decreased, possibly because more particles were agglomerated at the grain boundaries, resulting in a decrease in the solid solubility of $\mathrm{Cu}$ atom in the aluminum matrix.
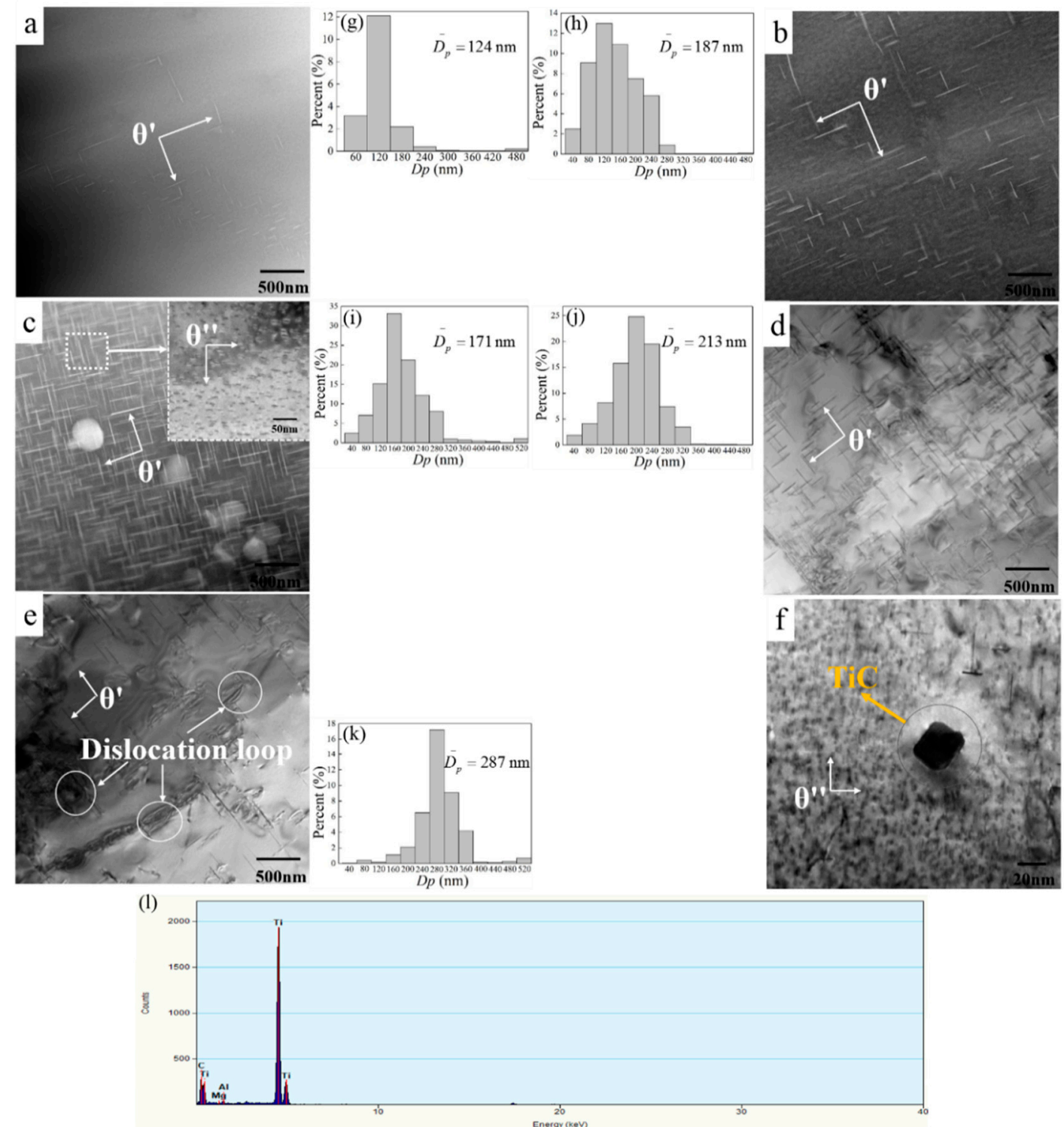

Figure 8. TEM micrographs of the forged and heat-treated TiC/2219 nanocomposite with different nanoparticle contents: (a) 0 wt.\%, (b) 0.5 wt.\%, (c) 0.9 wt.\%, (d) 1.3 wt.\%, and (e) 1.7 wt.\%. $(\mathbf{g}-\mathbf{k})$ the corresponding statistical results of the diameters of the $\theta^{\prime}$ precipitates in (a-f), respectively; (f) morphology of $\mathrm{TiC}$ nanoparticle in $0.9 \mathrm{wt} . \% \mathrm{TiC} / 2219$ nanocomposite; (1) the TEM-EDS of the TiC nanoparticle.

\subsection{Mechanical Properties}

Figure 9 shows the effect of different $\mathrm{TiC}$ nanoparticle contents on the ultimate tensile strength (UTS), yield strength (YS), and elongation of all the samples. The numerical results are listed in Table 1. Compared with the 2219 alloy, the strength and elongation of the composites significantly improved. 
The 0.9 wt.\% TiC/2219 composite exhibited the highest strength and ductility. Combined with the results shown in Figure $7 b$, this implied that the sample was strengthened by the $\theta^{\prime \prime}$ and $\theta^{\prime}$ phases because the nano-precipitated phases were limited and hindered the drive and motion of the dislocations by forcing the dislocations around the nano-precipitated phase. This played an important role in increasing the material strength. Therefore, the size and volume fraction of $\theta^{\prime \prime}$ and $\theta^{\prime}$ phases affected the final properties of the materials. As can be seen from Figure 8c, composite with a nanoparticle content of $0.9 \mathrm{wt}$ \% contains the highest number of precipitated $\theta^{\prime \prime}$ and $\theta^{\prime}$ phases, and thus exhibits a higher performance.

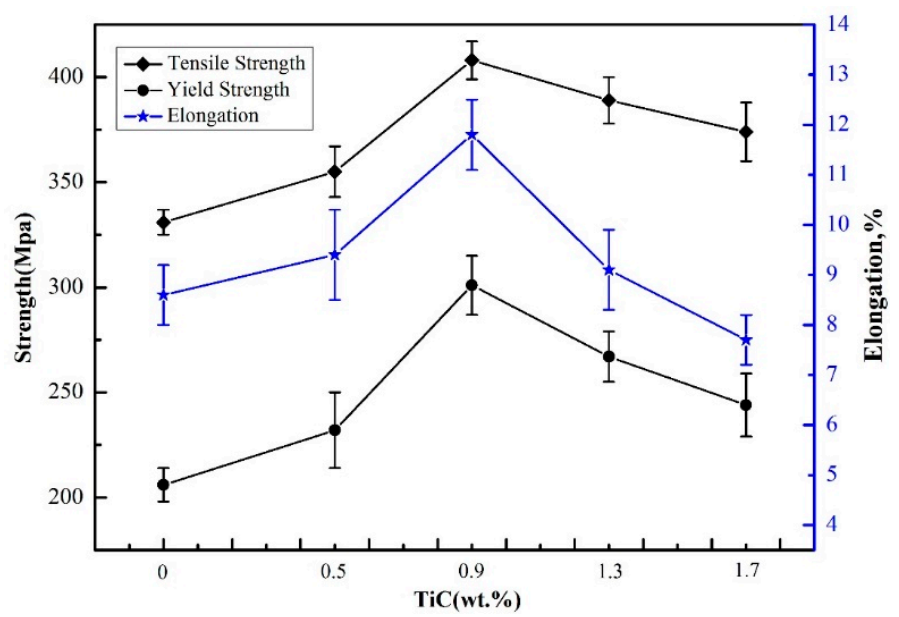

Figure 9. Mechanical properties of the TiC/2219 nanocomposites.

Table 1. The tensile data of the 2219 alloy and the $\mathrm{TiC} / 2219$ composites with different particle contents at a displacement speed of $2 \mathrm{~mm} / \mathrm{min}$.

\begin{tabular}{cccc}
\hline $\operatorname{TiC}(\mathbf{w t} . \mathbf{\%})$ & $\left.\boldsymbol{\sigma}_{\mathbf{0 . 2}} \mathbf{( M P a}\right)$ & $\boldsymbol{\sigma}_{\text {UTS }}(\mathbf{M P a})$ & $\boldsymbol{\delta}_{f}(\mathbf{\%})$ \\
\hline 0 & 206 & 331 & 8.6 \\
0.5 & 232 & 355 & 9.4 \\
0.9 & 301 & 411 & 11.8 \\
1.3 & 267 & 389 & 9.1 \\
1.7 & 244 & 374 & 7.7 \\
\hline
\end{tabular}

\subsection{Strengthening of TiC/2219 Nanocomposite}

The two major strengthening components in metal matrix composites (MMCs) included grain refinement and Orowan strengthening. After introducing the $\mathrm{TiC}$ nanoparticles, the grain refinement occurred with decreasing grain sizes. The smaller the grain sizes became, the more grain boundaries accommodated the plastic deformation. Usually, smaller grain size leads to higher yield strength (termed as Hall-Petch effect). Strengthening $\left(\Delta \sigma_{\mathrm{GR}}\right)$ from grain refinement in the MMCs is described in Equation (1) [32,33].

$$
\Delta \sigma_{\mathrm{GR}}=\mathrm{k}_{\mathrm{H}-\mathrm{P}}\left(\left(\mathrm{d}_{\mathrm{mmc}}\right)^{-1 / 2}-\left(\mathrm{d}_{\mathrm{mm}}\right)^{-1 / 2}\right)
$$

where $k_{H-P}, d_{m m c}$, and $d_{m m}$ are defined as the Hall-Petch coefficient, the grain sizes of reinforced MMCs, and the grains sizes of unreinforced pure alloy matrix, respectively. $\mathrm{k}_{\mathrm{H}-\mathrm{P}}$ is $74 \mathrm{MPa} \mu \mathrm{m}^{1 / 2}$ [34].

The dislocation-particle interaction induces a dislocation loop surrounding the particle, further stimulating an increase in the mechanical strength. This kind of particle-induced strengthening mechanism is termed as Orowan strengthening. Such increasing strength is proportional to the inverse of inter-particle spacing. Orowan strengthening $\left(\Delta \sigma_{\mathrm{OR}}\right)$ is quantitatively evaluated by Equation (2).

$$
\Delta \sigma_{\mathrm{OR}}=\frac{0.13 \boldsymbol{b} G_{m}}{d_{p}\left(8 V_{p}^{3}-1\right)} \ln \frac{d_{p}}{2 \boldsymbol{b}}
$$


In Equation (2), $\boldsymbol{b}$ represents the Burger's vector, $G_{m}$ is the shear modulus, $d_{p}$ designates the average nanoparticle size, and $V_{p}$ defines the volume fraction of nanoparticles. Regarding AA2219 Al alloy, the $G_{m}$ value is determined to be $25.4 \mathrm{GPa}$ at $300 \mathrm{~K}$ [35]. Burger's vector, $|b|$, is $\sim 0.286 \mathrm{~nm}$ for $\mathrm{Al}$ alloys [36]. $V_{p}$ designates the volume fraction of reinforcing nanoparticles. $V_{p}$ can be obtained by solving Equation (3) [37].

$$
\lambda=d_{p}\left[\left(\frac{1}{2 V_{p}}\right)^{\frac{1}{3}}-1\right]
$$

$\lambda$ in Equation (3) defines the inter-particle spacing. In the present $\mathrm{TiC} / 2219$ nanocomposite, $\lambda$ should be evaluated from the TiC nanoparticles sitting inside the $\alpha$-Al matrix grains rather than those agglomerating at the $\alpha-\mathrm{Al}_{1} \mathrm{Al}_{2} \mathrm{Cu}$ eutectic networks or grain boundaries.

By substituting all the critical parameters into Equations (1)-(3), the individual contribution of two strengthening mechanisms to the yield strength $(\sigma)$ of TiC/2219 nanocomposite with $0.9 \mathrm{wt} . \% \mathrm{TiC}$ can be calculated. Orowan strengthening made the most significant contribution to the yield stress, with $\Delta \sigma_{\text {Orowan }}$ value of $68.15 \mathrm{MPa}$. The value of $\Delta \sigma_{\mathrm{GR}}$ is $2.93 \mathrm{MPa}$.

\subsection{Fracture Behavior}

Figure 10 shows the fracture surfaces of the forged and heat-treated 2219 alloy and composites. Figure 10a shows that the fracture surface of the 2219 alloy has many coarse $\mathrm{Al}_{2} \mathrm{Cu}$ phases and shallow dimples along with very few tear ridges. The main fracture mode was a transgranular fracture. Figure 10b shows many tear ridges and some big deep dimples, and the main fracture mode was ductile. Figure 10c shows many small deep dimples and tearing edges, which impart high ductility. The magnified image shows that $\mathrm{TiC}$ nanoparticles were distributed evenly in the dimples. Hence, the $0.9 \mathrm{wt} . \% \mathrm{TiC} / 2219$ composite shows the best performance (Table 1). However, as the particle content increased, the number of dimples began to decrease and was accompanied by the coarse $\mathrm{Al}_{2} \mathrm{Cu}$ phases (Figure 10d). The fracture mode was characterized by a combination of toughness and brittleness. At a nanoparticle content of $1.7 \mathrm{wt} . \%$, the dimples became coarse and the amount of dimples decreased. In addition, the agglomerated nanoparticles were found at the grain boundaries (Figure 10e). In general, the ductile fracture was dominant. The uniformly dispersed nanoparticles in the matrix served as nucleation centers, resulting in the reduction of grain size. Therefore, more dimples were present on the fracture surface. With increasing nanoparticle content, more and more nanoparticles will accumulate at the grain boundaries forming clusters, which will cause some shrinkages and porosities, resulting in serious degradation of the material's mechanical properties. In addition, the agglomerated $\mathrm{TiC}$ nanoparticles lead to the formation of voids/porosities between neighboring particles, resulting in an uncompact microstructure. The areas with such loose microstructures will, in turn, deliver mechanical anisotropy. Consequently, the corresponding mechanical properties deteriorated. 

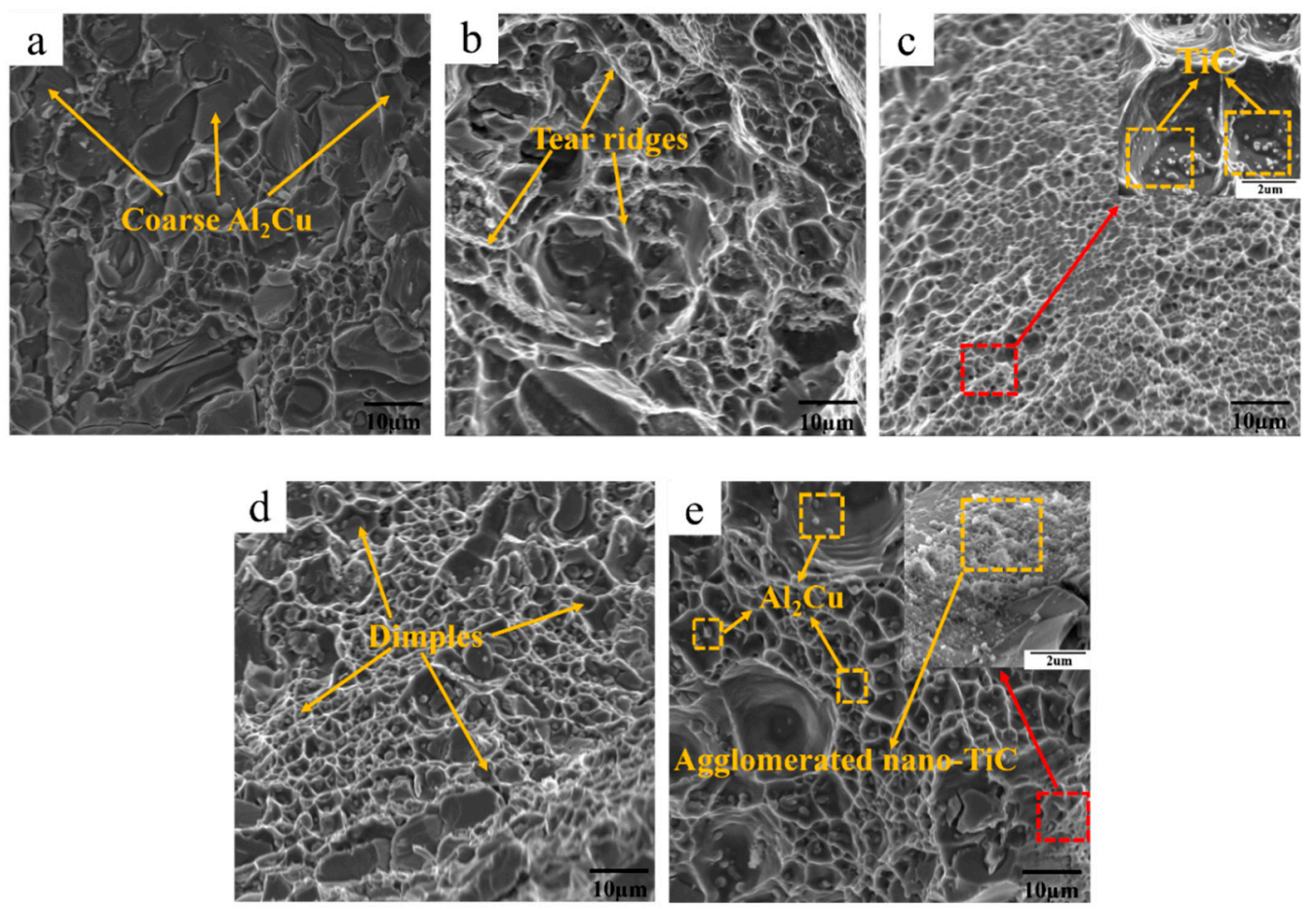

Figure 10. Fracture surfaces of the forged and heat-treated TiC/2219 nanocomposite with different nanoparticle contents: (a) 0 wt.\%, (b) $0.5 \mathrm{wt} . \%$, (c) $0.9 \mathrm{wt} . \%$, (d) $1.3 \mathrm{wt} . \%$, and (e) $1.7 \mathrm{wt} . \%$, respectively.

\section{Conclusions}

In this work, the effects of different nanoparticle content (mass fractions) on the precipitation phase of the forged and heat-treated $\mathrm{TiC} / 2219$ nanocomposites were studied. The following conclusions were drawn based on the obtained results:

(1) After solution aging, usually very few sub-grains would exist in the matrix for the 2219 alloy. However, there were still many sub-grains in composites with $1.3 \mathrm{wt} . \% \mathrm{TiC}$ and $1.7 \mathrm{wt} . \% \mathrm{TiC}$ as shown in the EBSD.

(2) An appropriate amount of $\mathrm{TiC}$ nanoparticles could promote the dissolution of $\mathrm{Al}_{2} \mathrm{Cu}$ particles during heat treatment. With increasing TiC nanoparticle content from $0 \mathrm{wt} . \%$ to $0.9 \mathrm{wt} . \%$, the area fraction of the $\mathrm{Al}_{2} \mathrm{Cu}$ phases decreased from $2.19 \%$ to $0.26 \%$ due to dissolution into the matrix. However, with increasing TiC nanoparticle content from $1.3 \mathrm{wt} . \%$ to $1.7 \mathrm{wt} . \%$, the area fraction of the $\mathrm{Al}_{2} \mathrm{Cu}$ phases increased from $0.83 \%$ to $1.16 \%$.

(3) For the forged and heat-treated composites, the addition of $\mathrm{TiC}$ nanoparticles facilitated the precipitation of $\theta^{\prime \prime}$ and $\theta^{\prime}$ phases during aging. At a nanoparticle content of $0.9 \mathrm{wt} . \%$, the largest amounts of $\theta^{\prime \prime}$ and the $\theta^{\prime}$ phases precipitated in the matrix. However, with a further increase in $\mathrm{TiC}$ nanoparticles content, the precipitation of the precipitated phase was inhibited. When TiC nanoparticles entered the Al matrix, it inevitably caused crystal lattice distortion and increased the system's energy. To maintain low system energy, more oversaturated vacancies might aggregate around the $\mathrm{TiC}$ nanoparticles. This was the reason for the many precipitates in the $0.9 \mathrm{wt} . \%$ $\mathrm{TiC} / 2219$ nanocomposite.

(4) The mechanical properties of the forged and heat-treated $0.9 \mathrm{wt} . \% \mathrm{TiC} / 2219$ nanocomposite were better than those of the 2219 alloy and other composites. The tensile strength, yield strength, and elongation of the forged $0.9 \mathrm{wt} . \% \mathrm{TiC} / 2219$ nanocomposite increased by $24.2 \%, 46.1 \%$, and $37.2 \%$, respectively, than those of the forged 2219 alloy. 
Author Contributions: Y.Y., R.J. and X.L. designed the experiments. Y.Y., R.L. and Y.Z. performed all experiments. Y.Y., R.J., and X.L. conducted the data analysis. Y.Y. and R.J. wrote the manuscript with assistance from X.L., and R.L.

Funding: This research was funded by the National Natural Science Foundation of China, Grant number: 51805549, Major Special Projects for Science and Technology in Hunan Province, Grant number: 2016GK1004 and Hunan Natural Science Foundation, Grant number: 2017JJ3391.

Conflicts of Interest: The authors declare no conflict of interest.

\section{References}

1. Jiang, J.; Dodd, B. Workability of aluminum-based metal-matrix composites in cold compression. Composites 1995, 26, 62-66. [CrossRef]

2. Ibrahim, I.A.; Mohamed, F.A.; Lavernia, E.J. Particulate reinforced metal matrix composites-A review. J. Mater. Sci. 1991, 26, 1137-1156. [CrossRef]

3. Vencl, A.; Bobic, I.; Arostegui, S.; Bobic, B.; Marinkovic, A.; Babic, M. Structural, mechanical and tribological properties of $\mathrm{A} 356$ aluminum alloy reinforced with $\mathrm{Al}_{2} \mathrm{O}_{3}, \mathrm{Si}-\mathrm{C}$ and $\mathrm{SiC}+$ graphite particles. J. Alloy. Compd. 2010, 506, 631-639. [CrossRef]

4. Yang, C.; Zhang, P.; Shao, D.; Wang, R.H.; Cao, L.F.; Zhang, J.Y.; Sun, J. The influence of Sc solute partitioning on the microalloying effect and mechanical properties of $\mathrm{Al}-\mathrm{Cu}$ alloys with minor Sc addition. Acta Mater. 2016, 119, 68-79. [CrossRef]

5. Wang, Z.; Xinbo, T.L.; Shao, H.H. Fabrication and properties of the TiC reinforced high-strength steel matrix composite. Int. J. Refract. Met. Hard Mater. 2016, 58, 14-21. [CrossRef]

6. Hugo, M.O.; Peter, E.; Hans, K. The history of the technological progress of hardmetals. Int. J. Refract. Met. Hard Mater. 2014, 44, 148-159. [CrossRef]

7. Huang, Z.Y.; Zhang, X.X.; Xiao, B.Y.; Ma, Z.Y. Hot deformation mechanisms and microstructure evolution of SiCp/2014Al composite. J. Alloy. Compd. 2017, 722, 145-157. [CrossRef]

8. Wu, K.; Deng, K.K.; Nie, K.B.; Wu, Y.W.; Wang, X.J.; Hu, X.S.; Zheng, M. Microstructure and mechanical properties of $\mathrm{SiCp} / \mathrm{AZ} 91$ composite deformed through a combination of forging and extrusion process. Mater. Des. 2010, 31, 3929-3932. [CrossRef]

9. Ezatpour, H.R.; Sajjadi, S.A.; Sabzevar, M.H.; Huang, Y.Z. An investigation of the tensile and compressive properties of Al6061 and its nanocomposites in as-cast state and in extruded condition. Mater. Sci. Eng. A 2014, 607, 589-595. [CrossRef]

10. Zhang, L.J.; Qiu, F.; Wang, J.G.; Jiang, Q.C. High strength and good ductility at elevated temperature of nano-SiCp/Al2014 composites fabricated by semi-solid stir casting combined with hot extrusion. Mater. Sci. Eng. A 2015, 626, 338-341. [CrossRef]

11. Jahedi, M.; Mani, B.; Shakoorian, S.; Pourkhorshid, E.; Paydar, M.H. Deformation rate effect on the microstructure and mechanical properties of Al-SiCp composites consolidated by hot extrusion. Mater. Sci. Eng. A 2012, 556, 23-30. [CrossRef]

12. Zhang, W.L.; Wang, J.X.; Yang, F.; Sun, Z.Q.; Gu, M.Y. Recrystallization kinetics of col-d-rolled squeeze-cast $\mathrm{Al} / \mathrm{SiC} / 15 \mathrm{w}$ composites. J. Compos. Mater. 2006, 40, 1117-1131. [CrossRef]

13. Kaur, L.; Pabla, B.S.; Dhami, S.S. A review on field areas of research in forging process using FEA. Int. J. Eng. Tech. Res. 2016, 5. [CrossRef]

14. Ozdemir, I.; Cocen, U.; Onel, K. The effect of forging on the properties of particulate-SiC-reinforced aluminum-alloy composites. Compos. Sci. Technol. 2000, 60, 411-419. [CrossRef]

15. Bharathesha, T.P.; Rameshb, C.S.; Keshavamurthyc, R.; Verma, S.M. Effect of Hot forging on Mechanical Characteristics of Al6061-TiO 2 Metal Matrix Composite. Mater. Today Proc. 2015, 2, 2005-2012. [CrossRef]

16. Ceschini, L.; Minak, G.; Morri, A. Forging of the AA2618/20 vol. $\% \mathrm{Al}_{2} \mathrm{O}_{3 p}$ composite: Effects on microstructure tensile properties. Compos. Sci. Technol. 2009, 69, 1783-1789. [CrossRef]

17. Murty, S.V.S.N.; Rao, B.N.; Kashyap, B.P. On the hot working characteristics of $6061 \mathrm{Al}-\mathrm{SiC}$ and $6061-\mathrm{Al}_{2} \mathrm{O}_{3}$ particulate reinforced metal matrix composites. Compos. Sci. Technol. 2003, 63, 119-135. [CrossRef]

18. Narayan, S.; Rajeshkannan, A. Hardness, tensile and impact behaviour of hot forged aluminum metal matrix composites. J. Mater. Res. Technol. 2017, 6, 213-219. [CrossRef] 
19. Gaisin, R.A.; Imayev, V.M.; Imayev, R.M. Effect of hot forging on microstructure and mechanical properties of near a titanium alloy/TiB composites produced by casting. J. Alloy. Compd. 2017, 723, 385-394. [CrossRef]

20. Kumar, G.B.V.; Rao, C.S.P.; Selvaraj, N. Mechanical and Tribological Behavior of Particulate Reinforced Aluminum Metal Matrix Composites-A review. J. Min. Mater. Charact. Eng. 2011, 10, 59-91. [CrossRef]

21. Li, R.Q.; Liu, Z.L.; Dong, F.; Li, X.Q.; Chen, P.H. Grain refinement of a large-scale Al alloy casting by introducing the multiple ultrasonic generators during Solidification. Metall. Mater. Trans. A 2016, 47, 3790-3796. [CrossRef]

22. Dong, G.; Li, X.Q.; Zhang, L.H.; Ma, L.Y.; Li, R.Q. Cavitation erosion mechanism of titanium alloy radiation rods in aluminum melt. Ultrason. Sonochem. 2016, 31, 150-156. [CrossRef] [PubMed]

23. Yang, Y.Y.; Liu, Z.L.; Jiang, R.P.; Li, R.Q.; Li, X.Q. Microstructural evolution and mechanical properties of the AA2219/TiC nanocomposite manufactured by ultrasonic solidification. J. Alloy. Compd. 2019, 811, 151991. [CrossRef]

24. He, H.L.; Yia, Y.P.; Huang, S.Q.; Zhang, Y.X. Effects of deformation temperature on second-phase particles and mechanical properties of 2219 Al-Cu alloy. Mater. Sci. Eng. A 2018, 712, 414-423. [CrossRef]

25. GB/T 228.1. Metallic Materials-Tensile Testing-Part 1: Method of Test at Room Temperature; Standards Press of China: Beijing, China, 2010.

26. Hu, H.E.; Zhen, L.; Zhang, B.Y.; Yang, L.; Chen, J.Z. Microstructure characterization of 7050 aluminum alloy during dynamic recrystallization and dynamic recovery. Mater. Charact. 2008, 59, 1185-1189. [CrossRef]

27. Elgallad, E.M.; Zhang, Z.; Chen, X.G. Effect of two-step aging on the mechanical properties of AA2219 DC cast alloy. Mater. Sci. Eng. A 2015, 625, 213-220. [CrossRef]

28. Biswas, A.; Siegel, D.J.; Wolverton, C.; Seidman, D.N. Precipitates in Al-Cu alloys revisited: atom-probe tomographic experiments and first-principles calculations of compositional evolution and interfacial segregation. Acta Mater. 2011, 59, 6187-6204. [CrossRef]

29. Ma, P.P.; Liu, C.H.; Wu, C.L.; Liu, L.M.; Chen, J.H. Mechanical properties enhanced by deformation-modified precipitation of $\theta^{\prime}$-phase approximants in an Al-Cu alloy. Mater. Sci. Eng. A 2016, 676, 138-145. [CrossRef]

30. Zhou, D.S.; Qiu, F.; Jiang, Q.C. Simultaneously increasing the strength and ductility of nano-sized TiN particle reinforced Al-Cu matrix composites. Mater. Sci. Eng. A 2014, 596, 98-102. [CrossRef]

31. Hardy, H.K.; Heal, T.J. Report on precipitation. Prog. Met. Phys. 1954, 5, 143-278. [CrossRef]

32. Malaki, M.; Xu, W.; Kasar, A.K.; Menezes, P.L.; Dieringa, H.; Varma, R.S.; Gupta, M. Advanced metal matrix nanocomposites. Metals 2019, 9, 330. [CrossRef]

33. Kim, C.S.; Sohn, I.; Nezafati, M.; Ferguson, J.; Schultz, B.F.; Bajestani-Gohari, Z.; Rohatgi, P.K.; Cho, K. Prediction models for the yield strength of particle-reinforced unimodal pure magnesium $(\mathrm{Mg})$ metal matrix nanocomposites (MMNCs). J. Mater. Sci. 2013, 48, 4191-4204. [CrossRef]

34. Wang, T.; Chen, Z.; Zheng, Y.; Zhao, Y.; Kang, H.; Gao, L. Development of $\mathrm{TiB}_{2}$ reinforced aluminum foundry alloy based in situ composites-Part II: Enhancing the practical aluminum foundry alloys using the improved Al-5wt.\% TiB 2 master composite upon dilution. Mater. Sci. Eng. A 2014, 605, 22-32. [CrossRef]

35. Liu, L.; Wu, Y.; Gong, H.; Li, S.; Ahmad, A. A physically based constitutive model and continuous dynamic recrystallization behavior analysis of 2219 aluminum alloy during hot deformation process. Materials 2018, 11, 1443. [CrossRef]

36. Dunand, D.C.; Mortensen, A. On plastic relaxation of thermal stresses in reinforced metals. Acta Metall. Mater. 1991, 39, 127-139. [CrossRef]

37. Zhang, Q.; Chen, D.L. A model for predicting the particle size dependence of the low cycle fatigue life in discontinuously reinforced MMCs. Scr. Mater. 2004, 51, 863-867. [CrossRef]

(C) 2019 by the authors. Licensee MDPI, Basel, Switzerland. This article is an open access article distributed under the terms and conditions of the Creative Commons Attribution (CC BY) license (http://creativecommons.org/licenses/by/4.0/). 